\title{
Causes Analysis and Preventive Measures of Blood Donation Reaction of University Student
}

\author{
Wei Feng*, Shuhua Qiu, Zhenming Deng and Tao Dong \\ Blood Center of Gui Zhou Province, Gui Yang, Gui Zhou 550001, China
}

\begin{abstract}
Objective: To analyze the causes of blood donation reaction of university students, propose appropriate preventive measures to avoid blood waste and ensure the quality of the blood. Methods: The university students in Guiyang city were selected from January to December 2014. The cases of blood donation reaction and the causes are analyzed on 7063 college students. Results: Among the 7063 college students, there are 292 students with blood donation reaction, the main cause is psychological factors, followed by fatigue before blood donation, not-ideal blood donation environment, limosis or starvation, etc. It occurs more in the first time donors. Blood donors with different times and posture have different adverse reactions. Conclusion: Constantly summarizing experiences, development and implementation of scientific and causable preventive measures, improving the environment for blood donation, strengthening the sense of responsibility and sense of service of blood collection personnel, strengthening psychological nursing, giving donors a warm caring and confidence as far as possible, making donors relax mind and in the best state can help to reduce and prevent the occurrence of blood donation reaction, organize more donators and college students to actively participate in blood donation, in order to promote vigorous, healthy and sustained development of voluntary blood donation. The blood donation adverse reactions of university students are related to the frequency of blood donation and posture, we have developed a series of preventive measures against the causes of blood donation adverse reactions to reduce the incidence of adverse reactions.
\end{abstract}

\author{
KEYWORDS \\ College students \\ Blood donation reaction \\ Preventive measure
}

\section{Introduction}

College students play an important role in blood donation, usually their blood qualified rate is better than other blood donors [1], so they are ideal low-risk donors. In most places, they are even the most stable and the most reliable source of blood, they also account for a certain proportion

\footnotetext{
Copyright $\odot 2016$ Wei Fenget al.

doi: $10.18686 /$ aem.v5i3.10

Received: August 4, 2016; Accepted: August 29, 2016; Published online: September 17, 2016

This is an open-access article distributed under the terms of the Creative Commons Attribution Unported License (http://creativecommons.org/ licenses/by-nc/4.0/), which permits unrestricted use, distribution, and reproduction in any medium, provided the original work is properly cited.

${ }^{*}$ Corresponding author: Blood Center of Gui Zhou Province, Gui Yang, Gui Zhou 550001, China. E-mail: weifeng1212@sina.com
}

of blood donors in our city. However, the relevant study confirmed that the incidence of blood donation reaction of college students is much higher than other adult populations [2]. Blood donation adverse reaction refers to the syndrome featured by a sharp decline in blood volume and autonomic function disorder due to physiology, psychology, blood sampling and other factors occurred during or after blood donation, donors may experience dizziness, blurred vision, nausea, vomiting, pale, cold sweats, weakness of limbs and other discomfortable symptoms, many students actively participated in blood donation encounter blood donation reaction during or after donation in their first blood donation, so they are unwilling or afraid to donate blood again, which affect the blood donation process, therefore, analyzing the causes of blood donation reactions of university students and preventive 
measure, providing causeable solutions to reduce response rates is very important. Analysis of Guiyang university students blood donation reaction rate and causes during January to December 2014 are as follows.

\section{Materials and Methods}

\subsection{General Information}

7063 university students was participate in blood donation during January to December 2014, 3,000 boys and 4063 girls, aged of 18 to 25 years, the mean was 21.4 years, mean body weight of $57 \mathrm{~kg}$. $75.4 \%$ of them are the first time for blood donation. Students who participate in blood donation will be screened strictly according to "donor health inspection standards". The blood donation is 200 $\mathrm{mL}$. Analysis of physical form and investigation of adverse reactions to blood donation are made.

\subsection{Method}

According to the Ministry of Health standards, all blood donors must go through consultation and medical clearance to donate blood. For the personal who meet the criteria for blood donation, detailed information registration is made and collect about $200 \mathrm{~mL}$ or $400 \mathrm{~mL}$ of whole blood according to individual circumstances and donor's wishes. Statistics and analysis are made from two aspects, one is the comparison of first blood donation and non-first blood donation; the other is the comparison of semi-horizontal position and sitting position, sitting position refers to that the angle formed between human and the ground is about 90 degree; semi-horizontal donation uses beach chairs with canvas as the main material, the angle with the ground is $\geq 140$ degree. According to records, if donors experience one of the following symptom: dizziness, cold sweats, nausea, vomiting, pale, palpitation, chest tightness, cold limbs, low blood pressure, decreased heart rate, loss of consciousness, convulsions, incontinence and others, it is counted as blood donation reaction. Analyze the causes for the occurrence of blood donation reaction of total 292 cases [3].

\section{Results}

\subsection{The main cause of blood donation reactions is psychological factors (Table 1)}

Table 1. The causes of blood donation reactions of 292 cases of college students.

\begin{tabular}{ccccc}
\hline Cause & $\begin{array}{c}\text { First time } \\
\text { donors }(\mathrm{n})\end{array}$ & $\begin{array}{c}\text { Repeated } \\
\text { donors }(\mathrm{n})\end{array}$ & Total $(\mathrm{n})$ & $\begin{array}{c}\text { Reaction } \\
\text { rate (\%) }\end{array}$ \\
\cline { 2 - 4 } & 230 & 62 & 292 & \\
\hline $\begin{array}{c}\text { Psychentonia } \\
\text { Limosis, }\end{array}$ & 132 & 40 & 172 & 58.90 \\
$\begin{array}{c}\text { Starvation } \\
\text { Hyposomnia, } \\
\quad \text { Fatigue }\end{array}$ & 55 & 16 & 71 & 24.31 \\
$\begin{array}{c}\text { Environment, } \\
\text { Other factors }\end{array}$ & 8 & 9 & 38 & 13.01 \\
\hline
\end{tabular}

\subsection{There are several reasons for college students} blood donate reactions

(1) Psychentonia, which is the common characteristics of the first time donors, some college students don't understand the knowledge of blood donation and their awareness is not correct, for example, they are afraid of anemia, physical decline or infection disease and others caused by blood donation, thereby have varying degrees ideological concerns and psychological fear. Of which there are some students fear venipuncture cause pain, especially when you see the lancets, their fear will increase sharply, prone to blood donation reaction. (2) Overfatigue before blood donation. Since a college student's major task is to learn, and some college students need to participate in physical training, if they don't have a good rest before blood donation, likely to cause syncope during blood collection. (3) The donation environment is not ideal. Students in our city mostly receive Blood Collection through driving the blood collecting vehicle to the school, the number of each collection is more, the personnel are crowded, the environment is noisy, and there is often a phenomenon of one donating and many personal for onlookers. During outdoors collection in summer, since the weather is hot, blood donors will wait for a long time in the sun, the emergence of blood donation reaction highly increases. (4) The poor nutritional status of donors. part of school life are relatively poor and some students family economic conditions are weaken, so some students have poor nutrition condition. (5) Lack of precautions before and after the blood donation and weaker protection awareness result in blood donation reaction [4].

\section{Preventive measures}

\subsection{The donors should undergo a strictly medical examination and consultation}

For voluntary unpaid blood donors, they should reasonably arrange the blood donation time, prepare for blood collection well, for example, college students' learning task is more onerous before exams, so the blood donation should be done later. Medical personnel should strictly enforce the medical standard of "donor health inspection requirements", comprehensively assess the physical fitness and state of mind of donors, personal who meet the required condition are allowed to donate blood.

\subsection{Fully disseminating the knowledge of blood donation and conducting supportive psychological intervention}

When the psychological stress reaction produced in the process of blood donation, namely individuals needs and the ability for meeting the individual needs, is unbalanced, and psychosomatic tensions exceed individual tolerance extent, a series of physiological changes will occur and then 
lead to blood donation reactions. Therefore, we must pay attention to the psychological guidance of college student to reduce fear and increase the psychological adaptation of the blood donation procedure. For unpaid blood donation, there is a cognitive process for donors, as for the problem of universal concern, and health care workers should give psychological guidance and answers by kind, warm, encouraging language, fully advertise and interpret knowledge of blood physiology, blood donation, blood donation and health and other unpaid blood donation scientific knowledge, explain each blood donation step and the causes, including basic health examination, laboratory test of blood, the basic process of blood collection and so on, so that they truly recognize the prescribed blood will not endanger health and scientific blood donation is conducive to health. To reduce the occurrence of blood donation reaction, inform donors to avoid limosis and drink water as much as possible before donating blood, drinking water not only can effectively increase blood volume, it can also ease the tense mood, ensure the normal blood vessels to dilate, avoid decrease of cardiac output. Once donating blood publicity is effectively conducted, more and more blood donors may talk about their blood donating experience with each other, thereby creating a huge boost to blood donation activities and effectively preventing and reducing the blood donation reaction due to mental stress, fear to some extent. Health care staff should strengthen the observation on students in the process of blood donation, if there is any abnormity, promptly take targeted nursing measures [5].

\subsection{Creating a good environment for blood donation}

The blood collection workers should go to school to choose site the day before blood donation, mainly consider well ventilated, spacious meeting rooms or training rooms, ensure blood sanitation, clean, good insulation in winter and heatstroke prevention in summer. Blood donors will donate blood in batches according to the process in order to reduce the condition of dutch concert and long waiting time, thereby creating a friendly, cordial atmosphere for voluntary blood donation. Practice has proved, a clean, quiet, warm blood donation environment allows donors to feel warm, happy, relaxed and may help to prevent and reduce blood donation reactions.

\subsection{Efforts to improve the quality of medical workers}

Medical worker should be initiative, enthusiastic, courtesy in the hospitality services; constantly strive for excellence and master venipuncture in technology, strive to venipuncture accuracy rate of $100 \%$, achieve blood collection by the first time of puncture as much as possible. Master the techniques of removing needles, not press the puncture at the moment of removing needles when blood collection is completed, the needle should exit the blood vessels in the absence of pressure, in order to avoid mechanical incise injury to the blood vessel wall by needle tip and pain. The puncture site should be pressed for 5-10 minutes after removing needle, pressing parts should not be massaged forcefully to prevent local congestion caused by subcutaneous hemorrhage. After blood collection is complete, urge donors not to rush to change position, in situ rest for 3-5 minutes and then slowly get up, reducing blood donation reaction caused by orthostatic hypotension. In the whole process of blood donation, the medical staff should take the initiative to communicate with blood donors in order to divert the attention of donors, reduce tension, fear, and inform precautions after donation [6].

\subsection{Treatment of blood donation reaction}

Careful observation, early detection of various signs of blood reactions should be made, once blood donation reaction occurs, the medical staff must be calm, busy but not chaotic, so as not to generate fear and doubts to donors which can cause a chain reaction. immediately suspend donation, the donors should be supine, keep head lower and feet higher, head turns to one side, loosen collar and belt to keep the airway open, close observation of changes in body temperature, blood pressure, pulse and respiration is made, and perform symptomatic treatment for blood donation reaction [7].

\section{Conclusion}

After the above treatment, the general blood donation reaction can be alleviated, the medical staff should do publicity and interpretation work, so that donors understand this reaction does not leave sequelae, eliminate its concerns. In addition, timely fill in donation record sheet, do feedback work of the donor. In short, the blood donation reaction is not only related to the health of donors and their understanding of unpaid blood donation, but also related to the development of unpaid blood donation, therefore, in the whole process of blood donation, health care workers must have a high sense of responsibility, observe and analyze the psychological and physiological changes of blood donors, eliminate their ideological concerns by medical theory and methods, properly prevent and treat blood donation reaction, so that the donors safely, happily complete donation with the best state of mind.

\section{Conflicts of interest}

These authors have no conflicts of interest to declare.

\section{Authors' contributions}

These authors contributed equally to this work. 


\section{Reference}

1. Wang HM, Yao P, Su H. Distribution of the unpaid blood donation population and blood test condition. Journal of Clinical Transfusion and Laboratory. 2008;10(2):190-192.

2. Zhu GY. Health education intervention effect on reducing blood donation reaction of college students. Chinese Journal of School Health. 2004;25(1):53-54.

3. Chen YZ, Zhuang XS. Discussion on relationship of environment and blood donation reaction. Chinese Primary Health Care. 2010;24(3):77-78.

4. Peng DB, Zhao H. Prevention of blood donation reaction of voluntary blood donors. Processings of academic conference of the Chinese society of blood and Clinical blood transfusion committee. 2003;256-257.

5. People's Republic of China Ministry of Health. China Blood Transfusion technical operation (Blood station Part). Tianjin: Science and Technology Press, 1997:3-5.

6. Zhang $A Q$, Lin $Y$, Chen JB. Analysis and comparison of volume of blood donation, frequency of blood donation and donation reaction. Chinese Journal of Blood Transfusion. 2005;18(5):398.

7. Guo JH, Liu Q, Zhou S. Investigation and analysis of the blood donation reaction of $400 \mathrm{~mL}$ blood donors. Chinese Journal of Blood Transfusion. 2004;17(2):114. 